ECCOMAS

\section{Proceedia}

COMPDYN 2021

$8^{\text {th }}$ ECCOMAS Thematic Conference on Computational Methods in Structural Dynamics and Earthquake Engineering

M. Papadrakakis, M. Fragiadakis (eds.) Streamed from Athens, Greece, 28 - 30 June 2021

\title{
OPTIMAL DESIGN OF TID-BASED SYSTEM FOR THE CONTROL OF WIND-INDUCED VIBRATION IN TALL BUILDINGS THROUGH CULTURAL ALGORITHM
}

\author{
Luis Lara-Valencia ${ }^{1 *}$, Mateo Ramírez-Acevedo ${ }^{1}$, José Brito ${ }^{2}$, Daniel Caicedo ${ }^{1}$ and Yosef \\ Farbiarz $^{1}$ \\ ${ }^{1}$ Universidad Nacional de Colombia \\ Carrera 80 N. ${ }^{\circ}$ 65-223, Núcleo Robledo. Medellín, Colombia. \\ lualarava@unal.edu.co,maramirezac@unal.edu.co,dcaicedod@unal.edu.co,jfarbiar@unal.edu.co \\ ${ }^{2}$ Universidade de Brasilia \\ CEP. 70910-900. Brasilia, Brasil \\ jlbrito@unb.br
}

\begin{abstract}
Controlling wind-induced vibrations as well as aerodynamic forces is an essential part of the structural design of tall buildings in order to guarantee the serviceability limit state of the structure. This paper presents a numerical investigation focused on finding the optimal design parameters of a Tuned Inerter Damper (TID) based system for the control of wind-induced vibration in tall buildings. The control system is based on the conventional TID, with the main difference that its location is changed from the ground level to the last two story-levels of the structural system. The TID tuning procedure is based on an evolutionary cultural algorithm in which the optimum design variables defined as the frequency and damping ratios are searched according to the optimization criteria of minimizing the root mean square (RMS) response of displacements at the nth story of the structure. A Monte Carlo simulation is used to represent the dynamic action of the wind in the time domain in which a time-series derived from the Davenport spectrum using eleven harmonic functions with randomly chosen phase angles was reproduced. The above-mentioned methodology is then applied on a case-study derived from a 37-story prestressed concrete building with $144 \mathrm{~m}$ height, in which the wind action overcomes the seismic action. The results showed that the optimally TID is effective to reduce the RMS response of displacements up to $37.12 \%$ which demonstrates the feasibility of the system for the control of wind-induced vibrations in tall buildings.
\end{abstract}

Keywords: Evolutionary Cultural Algorithm, Monte Carlo Simulation, Tuned Inerter Damper, Wind-Induced Vibrations. 


\section{INTRODUCTION}

In recent years, the construction of high-rise buildings has increased, using lightweight and high-strength materials. Those structures are typically more flexible and exhibit lower damping values, making them more vulnerable to vibration problems induced by wind loads [12]. Consequently, interest in the field of vibration control has increased, leading to the extensive application of passive control for wind loads. According to Kwok and Samali [1], for several decades, classic devices such as Tuned Mass Damper (TMD) have been implemented, which are composed of a mass attached to the building with a system of springs and dashpots that dissipates energy as a relative movement develops between the mass and structure. In that sense, Lazar [5] proposed a novel passive control system which is called Tuned Inerter Damper (TID), similar to the TMD but with the attached mass being replaced by the inerter device. This inerter is a negligible mass device proposed by Smith [2] that induces an equivalent mass amplification effect called inertance with a 1/200 ratio between the actual mass and the inertances, as demonstrated in laboratory investigations carried out by Papageorgiou \& Smith [3].

It has been shown that the use of inerter devices in control systems provides considerable improvements in controlling mechanical vibrations [7]. Different authors [14, 17, 18] have adapted the inerter device in classic TMDs, obtaining significant enhancements in the dynamic response of buildings under wind-induced vibrations. Subsequently, various authors have achieved large reductions in the vibrations of a building by applying TID as well as TMDI systems, overcoming the limitations of the large amounts of mass that have to be implemented in conventional TMDs [15, 26, 27].

This paper presents a numerical investigation focused on finding the optimal design parameters of a Tuned Inerter Damper (TID) based system for the control of wind-induced vibration in tall buildings. The control system is based on the conventional TID, with the main difference that its location is changed from the ground level to the last two story-levels of the structural system according to the recommendations provided in [15]. The TID tuning procedure is based on an evolutionary cultural algorithm in which the optimum design variables defined as the frequency and damping ratios were searched according to the optimization criteria of minimizing the root mean square (RMS) response of displacements at the $n t h$ story of the structure. A Monte Carlo simulation is used to represent the dynamic action of the wind in the time domain in which a time series derived from the Davenport spectrum is reproduced using eleven harmonic functions with randomly chosen phase angles. Effective results are expected with the implementation of optimized TID to reduce the RMS response of displacements.

\section{MATHEMATICAL MODELS OF A MDOF STRUCTURE EQUIPPED WITH TID-BASED SYSTEM}

The inerter is a two-terminal-one-port mechanical device proposed by Smith [2] with the property that the equal and opposite force applied at the terminals is proportional to the relative acceleration between the terminals. 


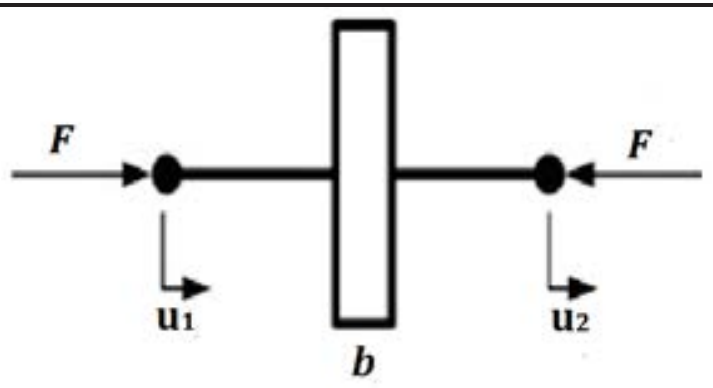

Figure 1: The symbol of inerter.

The mathematical notation corresponding to Figure 1 is:

$$
F=b\left(\ddot{u}_{2}-\ddot{u}_{1}\right)
$$

Where $\ddot{u}_{1}$ and $\ddot{u}_{2}$ represents the relative acceleration between its nodes and the constant $b$ is called the inertance.

The main focus of this work is to apply the variant of the TID proposed by Caicedo in [15]. Figure 2 presents a 2D shear frame with $n$ horizontal DOF at each level of the building and wind loads applied at each level. It is observed that the TID is positioned in the last two levels with $m_{i}, k_{i}$ and $c_{i}$ as the mass, lateral stiffness and damping coefficients of each story level $(i=1,2, \ldots, n)$. Additionally, $k_{d}$ and $c_{d}$ are the stiffness and damping that define the behavior of the TID. These two last variables can be rewritten as:

$$
\begin{gathered}
k_{d}=\omega_{s}^{2} f^{2} b \\
c_{d}=2 f \xi_{d} \omega_{s} b
\end{gathered}
$$

In equations (2) and (3), $\omega_{s}, f$ and $\xi_{d}$ are the fundamental circular frequency of the structural system, the frequency and damping ratios between the structure and the TID.

The design procedure to be carried out in this work consists of finding the optimal frequency ratio and damping ratio to minimize the dynamic response of the structure. 


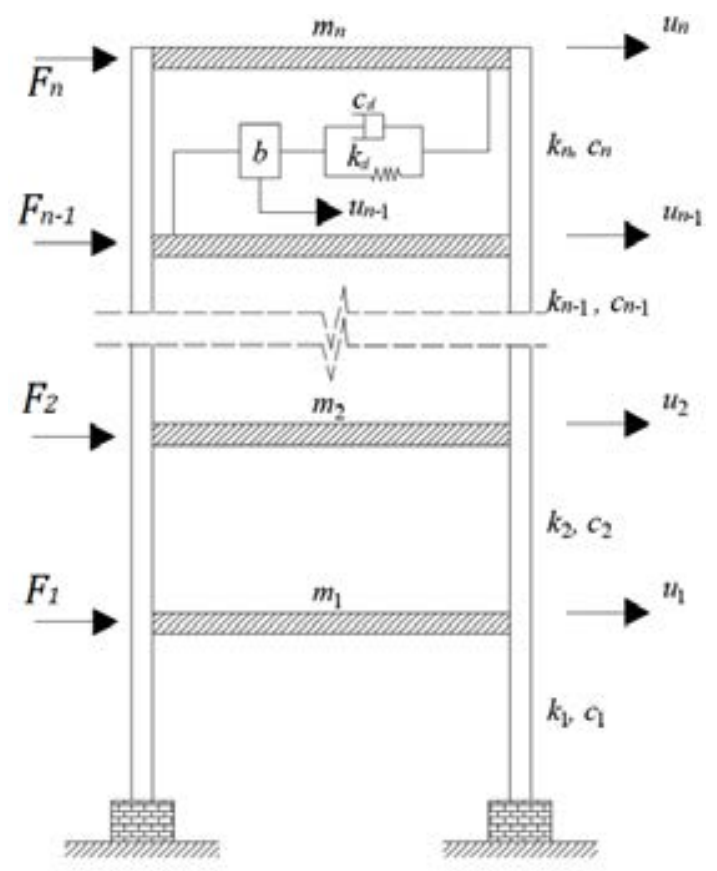

Figure 2: 2D frame equipped with a TID in the last two levels.

The following dynamic equilibrium equations describe the behavior of the $n$ degrees of freedom of each level of the structural system, and the additional degree of freedom $(n+1)$ given the possibility of horizontal movement of the TID.

$$
\begin{gathered}
m_{1} \ddot{u}_{1}+\left(c_{1}+c_{2}\right) \dot{u}_{1}-c_{2} \dot{u}_{2}+\left(k_{1}+k_{2}\right) u_{1}-k_{2} u_{2}=F_{1}(t) \\
m_{2} \ddot{u}_{2}-c_{2} \dot{u}_{1}+\left(c_{2}+c_{3}\right) \dot{u}_{2}-c_{3} \dot{u}_{3}-k_{2} u_{1}+\left(k_{2}+k_{3}\right) u_{2}-k_{3} u_{3}=F_{2}(t) \\
m_{n-1} \ddot{u}_{n-1}-c_{n-1} \dot{u}_{n-2}+\left(c_{n-1}+c_{n}+c_{d}\right) \dot{u}_{n-1}-c_{n} \dot{u}_{n}-c_{d} \dot{u}_{n+1}-k_{n-1} \dot{u}_{n-2} \\
+\left(k_{n-1}+k_{n}+k_{d}\right) u_{n-1}-k_{n} u_{n}-k_{d} u_{n+1}=F_{n-1}(t) \\
m_{n} \ddot{u}_{n}-c_{n} \dot{u}_{n-1}+\left(c_{n}+c_{d}\right) \dot{u}_{n}-c_{n} \dot{u}_{n}-c_{d} \dot{u}_{n+1}-k_{n} u_{n-1}+\left(k_{n}+k_{d}\right) u_{n}-k_{d} u_{d}=F_{n}(t) \\
b \ddot{u}_{n+1}-c_{d} \dot{u}_{n-1}-c_{d} \dot{u}_{n}+c_{d} \dot{u}_{n+1}-k_{d} u_{n-1}-k_{d} u_{n}+k_{d} u_{n+1}=\frac{1}{200} b F_{n+1}(t)
\end{gathered}
$$

Where the constant $1 / 200$ denotes the ratio between the physical mass of the TID and the inertance $(b)$. The ratio is assumed according to Papageorgiou and Smith [3] and Papageorgiou et al. [26].

Therefore, the System of Equations can be written in matrix form, corresponding to the general equation of motion:

$$
\begin{gathered}
\boldsymbol{M} \ddot{\boldsymbol{U}}(t)+\boldsymbol{C} \dot{\boldsymbol{U}}(t)+\boldsymbol{K} \boldsymbol{U}(t)=\boldsymbol{F}(\boldsymbol{t}) \\
\boldsymbol{M}=\left[\begin{array}{cccccc}
m_{1} & 0 & \cdots & 0 & 0 & 0 \\
0 & m_{2} & \cdots & 0 & 0 & 0 \\
\vdots & \vdots & \ddots & \vdots & \vdots & \vdots \\
0 & 0 & \cdots & m_{n-1} & 0 & 0 \\
0 & 0 & \cdots & 0 & m_{n} & 0 \\
0 & 0 & \cdots & 0 & 0 & b
\end{array}\right]
\end{gathered}
$$




$$
\begin{aligned}
& \boldsymbol{C}=\left[\begin{array}{cccccc}
c_{1}+c_{2} & -c_{2} & \cdots & 0 & 0 & 0 \\
-c_{2} & c_{2}+c_{3} & \cdots & 0 & 0 & 0 \\
\vdots & \vdots & \ddots & \vdots & \vdots & \vdots \\
0 & 0 & \cdots & c_{n-1}+c_{n}+c_{d} & -c_{n} & -c_{d} \\
0 & 0 & \cdots & -c_{n} & c_{n}+c_{d} & -c_{d} \\
0 & 0 & \cdots & -c_{d} & -c_{d} & c_{d}
\end{array}\right] \\
& \boldsymbol{K}=\left[\begin{array}{cccccc}
k_{1}+k_{2} & -k_{2} & \cdots & 0 & 0 & 0 \\
-k_{2} & k_{2}+k_{3} & \cdots & 0 & 0 & 0 \\
\vdots & \vdots & \ddots & \vdots & \vdots & \vdots \\
0 & 0 & \cdots & k_{n-1}+k_{n}+k_{d} & -k_{n} & -k_{d} \\
0 & 0 & \cdots & -k_{n} & k_{n}+k_{d} & -k_{d} \\
0 & 0 & \cdots & -k_{d} & -k_{d} & k_{d}
\end{array}\right] \\
& \boldsymbol{U}=\left\{\begin{array}{llllll}
u_{1} & u_{2} & \cdots & u_{n-1} & u_{n} & u_{n+1}
\end{array}\right\}^{T} \\
& \boldsymbol{\delta}=\left\{\begin{array}{llllll}
1 & 1 & \cdots & 1 & 1 & 1 / 200
\end{array}\right\}^{T}
\end{aligned}
$$

Where $\boldsymbol{M}, \boldsymbol{C}$ and $\boldsymbol{K}$ are the mass, stiffness and damping matrices, and $\boldsymbol{U}$ is defined as the structure displacement response.

\section{TID DESIGN AND OPTIMIZACIÓN PROCEDURE THROUGH CULTURAL ALGORITHM}

This work intends to implement a cultural algorithm for the optimal design of a TID. The cultural algorithm was first presented by Reynolds in [9] as a complementary algorithm to the evolutionary computation and natural selection algorithms. Cultural algorithms have been used for the solution and optimization of multiple engineering problems, such as the vibration control of vehicles or the design of stabilizers for power systems [10,11].

Figure 3, shows of the three components of the cultural algorithm. The first of the three components are the population space, which includes the population to be developed and the evaluation, reproduction, and modification mechanism. The second component is the belief space, representing the direction in which the population has to seek solutions. Finally, the third component of the cultural algorithm is made up of the communication protocol, through which the population and beliefs interact [9]. The functions in Figure 3 are defined as follows:

- Acceptance function: transfers individual knowledge that satisfies the aptitude value to belief space.

- Update function: adjusts the knowledge of the belief space according to the individual knowledge transferred.

- Influence function: adjusts the individual knowledge of the population space according to the knowledge of the belief space.

- Fitness function: produces the individual knowledge of the next generation according to certain rules. 


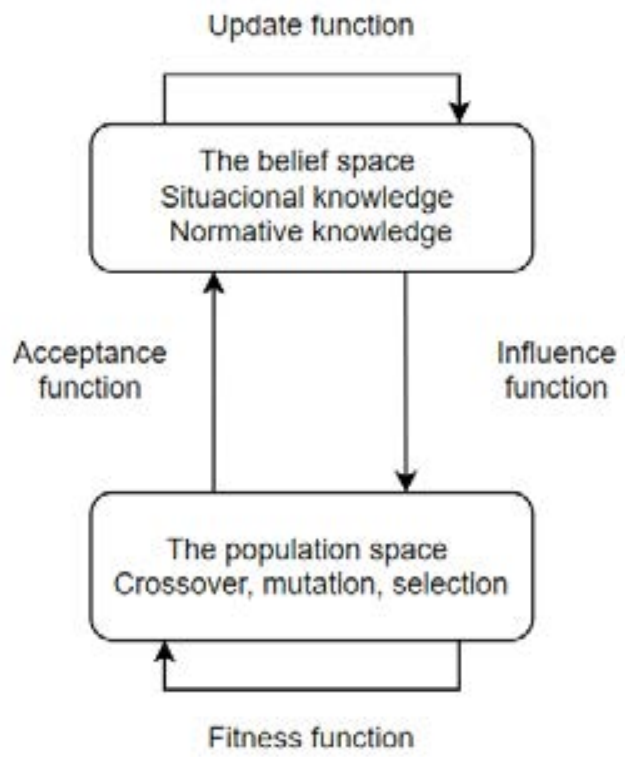

Figure 3: Framework of cultural algorithms.

The objective function defined in Eq. 15 will assess the performance of the control system applied to the case-study structure. This will be determined by means of the dynamic root mean square (RMS) response of displacements of the last floor of the structure.

$$
F_{o b j}=\frac{\text { RMS of the } n^{\text {th }} \text { DOF controlled response }}{\text { RMS of the } n^{\text {th }} \text { DOF uncontrolled response }}
$$

\section{WIND EXCITATION MODEL AND FREQUENCY DOMAIN ANALYSIS FOR THE TID-EQUIPPED SYSTEM}

To model the dynamic wind action, a computational simulation based on the Monte Carlo method is carried out, following the recommendations provided by Franco [21]. The procedure is based on the wind power spectrum developed by Davenport [23] through which it is possible to separate fluctuating pressure into $m$ harmonic functions (at least 11), one of which will be resonant. The Monte Carlo method and the Fourier transform are used to reproduce the fluctuating pressures of the wind.

The building is used as case-study in this investigation. The building, which is the tallest residential tower in Medellín, with $144 \mathrm{~m}$ in height, distributed over 37 floors. The location and topographical characteristics of the building are used to obtain the basic parameters to be used in the Synthetic Wind Method. These parameters were taken from the Colombian code, Reglamento Colombiano de Construcción Sismo Resistente (NSR-10) [24]

\section{NUMERICAL RESULTS AND DISCUSSION}

Following the procedure exposed previously and the mathematical formulation described in [19-22], it is possible to obtain the fluctuating pressures as shown in Figure 4. 


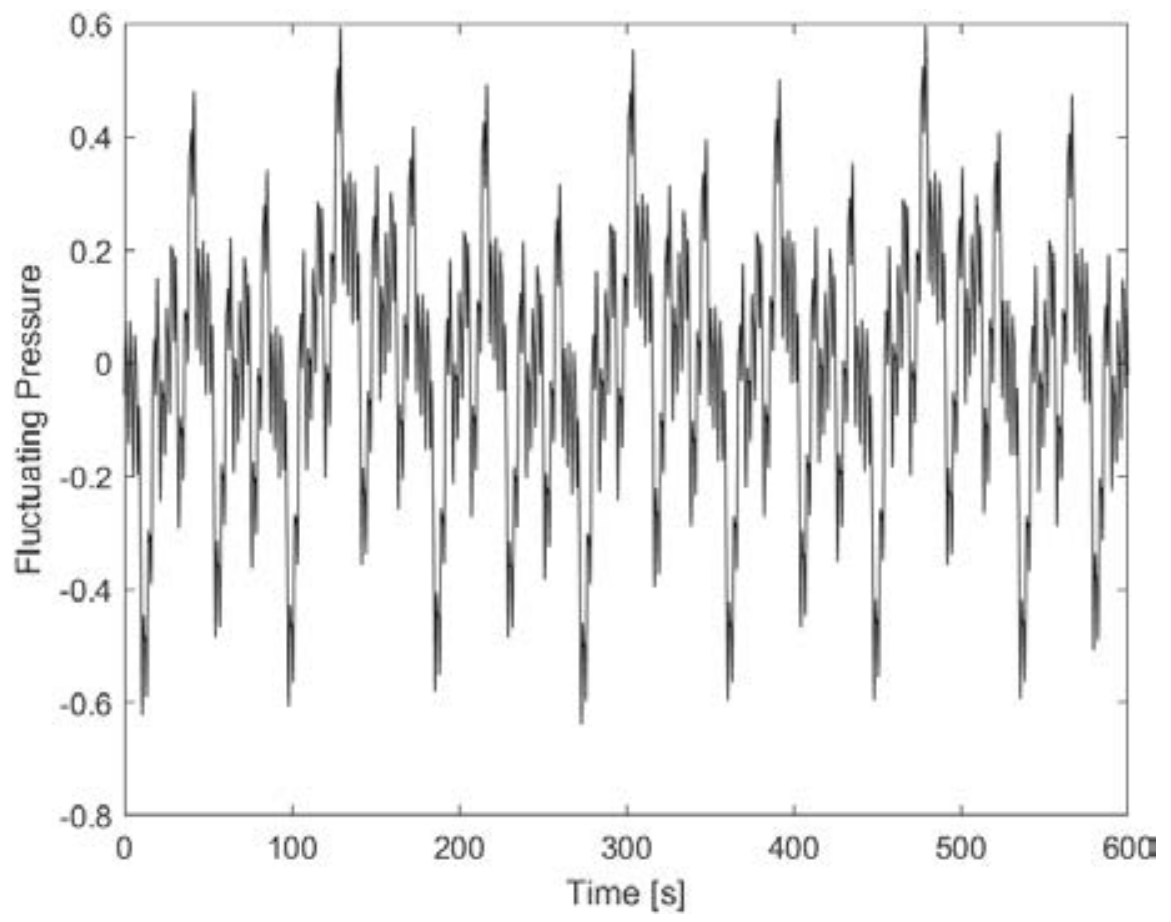

Figure 4: Fluctuating Pressure.

Now, the fluctuating forces over 600 seconds are computed from the fluctuating pressures [25]. It is worth noting that twenty simulations of fluctuating forces were performed to determine the highest displacements achieved at each simulation. Then, a unique fluctuating force is selected to generate a maximum displacement with a $95 \%$ probability of occurrence, following a Gumbel extreme value distribution. Figure 5 shows the time histories of wind loads on the 37 th floor of the building.

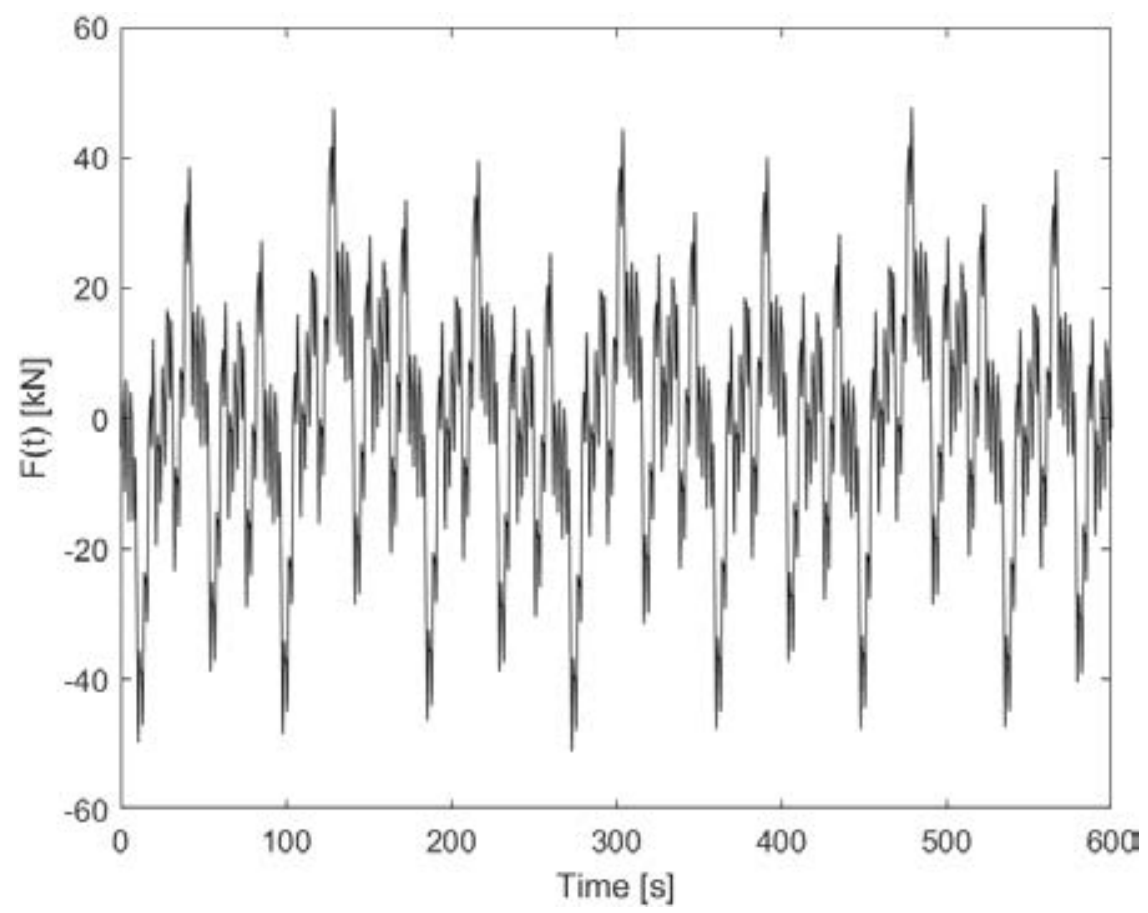

Figure 5: Time histories of wind loads on the $37^{\text {th }}$ floor of the building. 
Table 1 reports the design parameters optimized with the Cultural Algorithm. The optimization was carried out considering fixed $b$ values, which represent $2 \%, 5 \%$ and $20 \%$ of inertance ratios.

\begin{tabular}{cccc}
\hline $\boldsymbol{b}$ & $\boldsymbol{f}$ & $\boldsymbol{\zeta}_{\mathbf{d}}$ & $\mathbf{F}_{\mathbf{o b j}}$ \\
\hline $2 \%$ & 0.9882680 & 0.0000000 & 0.62616 \\
$5 \%$ & 0.5000000 & 0.5000000 & 0.68861 \\
$20 \%$ & 0.5000000 & 0.0219307 & 0.73547 \\
\hline
\end{tabular}

Table 1: Optimal design parameter for the TID.

On the other hand, Table 2 reports the RMS values of the displacements for the uncontrolled and controlled structure. Furthermore, the percentage of reduction of the RMS is presented as well.

\begin{tabular}{ccccc}
\hline & $\boldsymbol{b}$ & $\begin{array}{c}\text { Uncontrolled } \\
\text { Response }[\mathbf{m}]\end{array}$ & $\begin{array}{c}\text { Controlled } \\
\text { response }[\mathbf{m}]\end{array}$ & \% Reduction \\
\hline & $2 \%$ & 0.17363 & 0.10914 & $37.12 \%$ \\
& $5 \%$ & 0.17363 & 0.11954 & $31.15 \%$ \\
\hline \multirow{2}{*}{ Table 2: Maximum RMS response of displacements of 37th story }
\end{tabular}

Figure 6 shows the variation of the RMS values of the displacements of each degree of freedom considered. With these results, the efficiency of the TID is demonstrated.

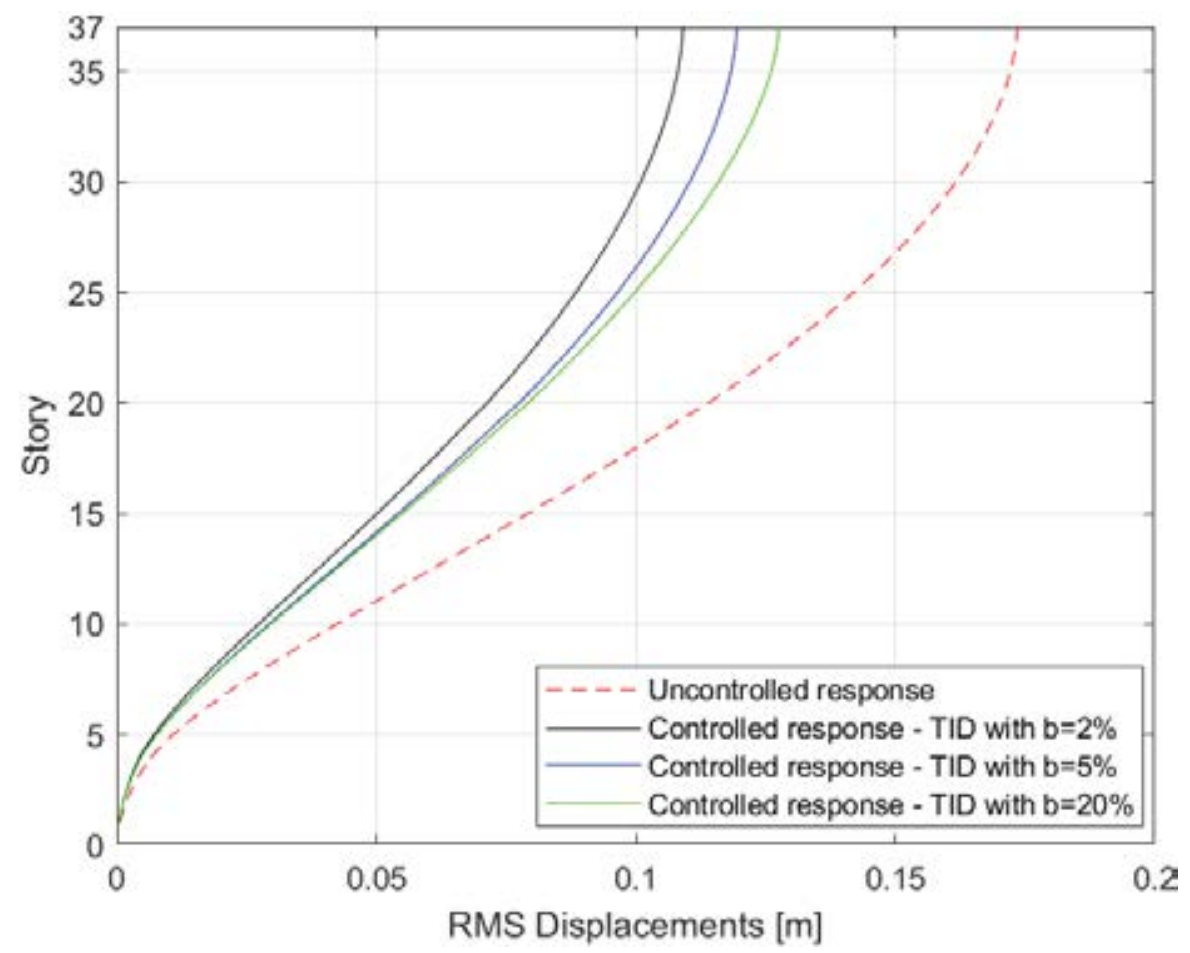

Figure 6: RMS displacement at each story level. 
The maximum uncontrolled RMS response of displacement at the 37th story level in Figure 6 is $0.173 \mathrm{~m}$. The reductions achieved using the optimized TID decrease between $37.12 \%$ and $26.45 \%$, as inertance values increase. Using the $b=2 \%$ TID, the maximum RMS displacement value is $0.109 \mathrm{~m}(37.12 \%$ reduction); with $b=5 \%$, the maximum RMS value diminish to $0.119 \mathrm{~m}(31.15 \%$ reduction); finally, with the $b=20 \% \mathrm{TID}$, the RMS value of displacement reduce hardly to $0.128 \mathrm{~m}(26.45 \%$ reduction). Thus, it is clear that the best reductions in the dynamic response, under wind excitations, are attained using the TID with the lowest inertance value $(b=2 \%)$.

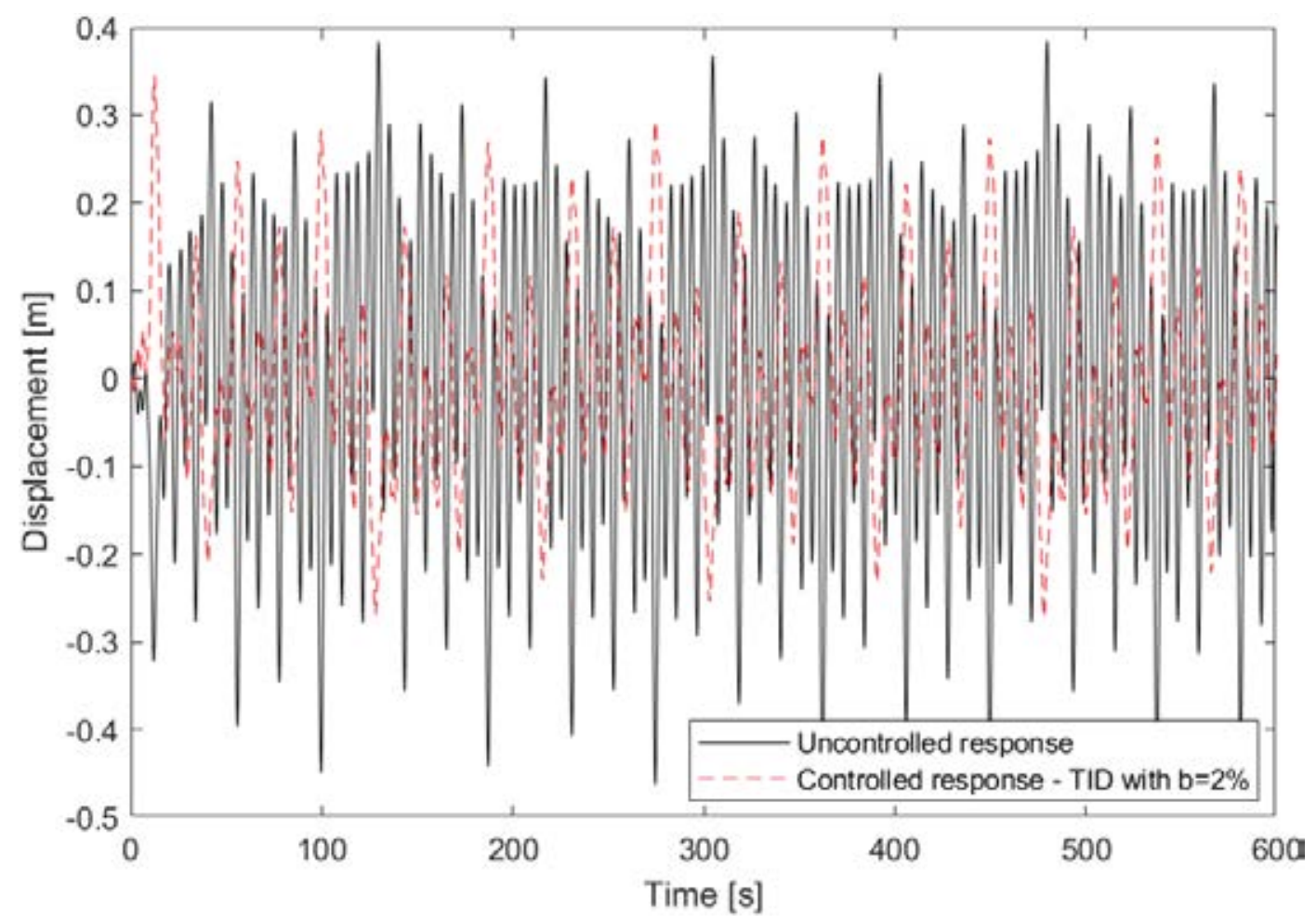

Figure 7: Time histories of controlled displacement on the $37^{\text {th }}$ floor of the building.

Finally, Figure 7 shows a comparison between the uncontrolled and controlled history of displacements on the 37 th floor of the structure. The peak displacement in Figure 7 was reduced from $0.463 \mathrm{~m}$ to $0.345 \mathrm{~m}$ using the $\mathrm{b}=2 \%$ TID, which represents a $25.48 \%$ overall reduction.

\section{CONCLUSIONS}

- A numerical investigation on the optimal design parameters of a Tuned Inerter Damper (TID) based system for the control of wind-induced vibration in tall buildings was presented in this paper. The control system was inspired by the conventional TID, with the main difference that its location was changed from ground level to the last two levels of the structural system. To represent the dynamic action of the wind in the time domain, a Monte Car-lo simulation was used in which a time series derived from the Davenport spectrum was re-produced using eleven harmonic functions with randomly chosen phase angles.

- The obtained results shows that TIDs with lower inertance values installed at the last floors of the building are useful to reduce the dynamic response of the structure under wind loads. Reductions up to $37.12 \%$ were achieved for RMS values of displacement us- 
ing $b=2 \%$ TID. Moreover, the cultural algorithm proved to be an efficient and useful tool for determining the optimal TID de-sign parameters, and the effectiveness of modified TID systems on mitigating wind-induced vibrations in high-rise buildings was demonstrated.

\section{ACKNOWLEDGEMENTS}

The authors are grateful for the support provided by the Universidad Nacional de Colombia - Sede Medellín for the development of this work.

\section{REFERENCES}

[1] K.C. Kwok, B. Samali, Performance of tuned mass dampers under wind loads. Vol. 17. Butterworth-Heinemann, 1995.

[2] M.C. Smith. Synthesis of Mechanical Networks: The Inerter. Proceedings of the $41^{\text {st }}$ IEEE, Conference on Decision and Control, Las Vegas, Nevada, USA, December, 2002.

[3] C. Papageorgiou, M.C. Smith. Laboratory experimental testing of inerters. In Proceedings of the 44th IEEE Conference on Decision and Control (IEEE 2005), Seville, Spain, December 12-15, 2005.

[4] I.F. Lazar, S.A. Neild, D.J. Wagg. Using an inerter-based device for structural vibration suppression. Earthquake Engineering \& Structural Dynamics, 43, 1129-1147, 2014.

[5] I.F. Lazar, S.A. Neild, D.J. Wagg. Design and Performance Analysis of Inerter-Based Vibration Control Systems. In Dynamics of Civil Structures, 4, 493-500. Springer, Cham, 2014.

[6] I.F. Lazar, S.A. Neild, D.J. Wagg. Inerter-based vibration suppression systems for laterally and base-excited structures. In Proceedings of the $9^{\text {th }}$ International Conference on Structural Dynamics (EURODYN 2014), Porto, Portugal, 30 June - 2 July, 2014.

[7] M.Z. Chen, Y. Hu. Inerter and Its Application in Vibration Control Systems. Springer, Singapore, 2019.

[8] Y. Wen, Z. Chen, X. Hua. Design and evaluation of tuned inerter-based dampers for the seismic control of MDOF structures. Journal of Structural Engineering, 143, 2017.

[9] R.G. Reynolds. An introduction to Cultural Algorithms. Proceedings of the Third Annual Conference on Evolutionary Programming, 131-139. River Edge, New Jersey, 1994.

[10] W. Wang, Y. Song, Y. Xue, H. Jin, J. Hou, M. Zhao. An optimal vibration control strategy for a vehicle's active suspension based on improved cultural algorithm. Applied Soft Computing, 2014.

[11] A. Khodabakhshian, R. Hemmati. Multi-machine power system stabilizer design by using cultural algorithms. Electrical power and Energy Systems, 2021.

[12] M.Y. Liu, W.L. C, J.H. Hwang, C.R. Chu. Wind-induced vibration of high-rise building with tuned mass damper including soil-structure interaction. Journal of Wind Engineering and Industrial Aerodynamics, 96, 1092-1102, 2007.

[13] A.A. Momtaz, M.A. Abdollahian. Study of Wind-induced vibrations in tall buildings with tuned mass dampers taking into account vortices effects. International Journal of Advanced Structural Engineering, 9, 385-395, 2017. 
[14] A. Giaralis, M. ASCE, F. Petrini. Wind-Induced Vibration Mitigation in Tall Buildings Using the Tuned Mass-Damper-Inerter. J. Struct. Eng, 143: 04017127, 2017.

[15] D.A. Caicedo. A comparative analysis on the seismic behavior of buildings using inerter-based devices: Tuned Mass Damper Inerter (TMDI) and Tuned Inerter Damper (TID). Dissertation. Medellín, Colombia, 2020.

[16] K.C. Kwok. Perception of vibration and occupant comfort in wind-excited tall buildings. Journal of Wind Engineering and Industrial Aerodynamics, 97, 368-380, 2009.

[17] A. Giaralis, F. Petrini. Optimum design of the tuned mass-damper-inerter for serviceability limit state performance in wind-excited tall buildings. X International Conference on Structural Dynamics (EURODYN 2017), 199, 1773-1778, 2017.

[18] F. Petrini, A. Giaralis, Z. Wang. Optimal tuned mass-damper-inerter (TMDI) design in windexcited tall buildings for occupants' comfort serviceability performance and energy harvesting. Engineering Structures. 2019.

[19] H.H. Barrios, N. Mosqueda, I. Huergo. Respuesta eólica de estructuras tipo punto ante viento sintético. XXI Congreso Nacional de Ingeniería Estructural, Sociedad Mexicana de Ingeniería Estructural. Campeche, Campeche, 2018.

[20] M.J. Ribeiro. Análise estática e dinâmica de torres metálicas autoportantes. Dissertaçao de Mestrado, Publicação DM 001A/00. Departamento de Engenharia Civil e Ambiental, Universidade de Brasilia, Brasilia, DF, 2000.

[21] M. Franco. Direct Along-Wind Dynamic Analysis of Tall Structures. Departamento de Engenharia de Estruturas e Fundações, Escola Politécnica da Universidade de São Paulo. São Paulo, 1993.

[22] H.O. Sasquia. Vento sintético e a simulação de Monte Carlo - uma forma de considerar a característica aleatória e instável do carregamento dos ventos em estruturas. Exacta, 7, 77-85, Universidade Nove de Julho, São Paulo, Brasil, 2009.

[23] A.G. Davenport. The spectrum of horizontal gustiness near the ground in high winds. Dept. of Civil Engineering, University of Bristol, 1961.

[24] ASOCIACIÓN COLOMBIANA DE INGENIERÍA SÍSMICA. Normas Colombianas de Diseño y Construcción Sismo-Resistente, NSR-10, AIS, Bogotá, 2010.

[25] Associação Brasileira de Normas Técnicas. NBR 6123 - Forças devidas ao vento nos edifícios. ABNT, Rio de Janeiro, 1988.

[26] Z. Chang, B. Fitzgerald. Tuned mass-damper-inerter (TMDI) for suppressing edgewise vibration of wind turbine blades. Engineering Structures, 221, 2020.

[27] F. Qian, Y. Luo, H. Sun, W.C. Tai, L. Zuo. Optimal tuned inerter dampers for performance enhancement of vibration isolation. Engineering Structures, 198, 2019. 